\title{
The patient at risk in dentistry: Behavioral and medico-legal recommendations
}

\author{
Emilio Nuzzolese
}

Forensic Odontologist, Bari, Italy

Address for correspondence: Emilio Nuzzolese, Forensic Odontologist, Bari, Italy. E-mail: emilionu@tin.it

Received: January 18, 2016

Accepted: May 04, 2016

e-Published: June 21, 2016

\begin{abstract}
Developments in medical science have led to an increase in human life expectancy and allow for the management and treatment of systemic conditions which in the past had a low survival rate. The technical development of biomaterials and electro-medical instruments, changing lifestyles and of morbidity leads to a broadening of the class of so-called patients "at risk." Dentists need a more careful analysis of the clinical risks involved; the approach should be firstly medical and then dental. The dentist must consider both technological and medical-legal aspects, sticking with the principle of risk versus benefit, and not exclude postponing dental treatments if indicated. The main safeguard for the patient at risk is a more extensive anamnesis, combined with a complete observation to identify or recognize conditions that are potentially hazardous. The author offers some reflections on the conduct to be adopted to cure safely, but also to avoid any judicial proceeding. Profiles of professional liability may, in fact, result from failing to follow care guidelines for that particular state of the clinical risk. However, the private nature of dental care and the code of medical ethics also allow the clinician the choice of not treating the patient if it is believed that the clinical risk and any medical emergency could not be dealt properly, or that oral health pathologies may require a more complex medical structure with the simultaneous presence of other specialists.
\end{abstract}

KEY WORDS: Forensic sciences, forensic odontology, clinical risk, legal medicine, morbidity

\section{INTRODUCTION}

Dentistry has changed a lot in the last two decades, both in the technological evolution of biomaterials and electromedical instruments and also for the type of patients treated. Developments in medical science have contributed to the increase human life expectancy and allow for the management and treatment of systemic conditions which in the past had a low survival rate. There are four particular behaviors which lead to key metabolic/physiological changes: Tobacco use, physical inactivity, unhealthy diet, the excessive use of alcohol, and other preventable risk factors such as childhood malnutrition and unsafe sex. At a global level, in fact, life expectancy has increased by 6 years since 1990 with a global life expectancy at birth of 68.1 for men and 72.7 for women [1]. In Italy life expectancy at birth has risen to 79.57 years [2]. Currently, the number of people over the age of 75 living in Italy is 298,143, of which 195,421 are over 85 -year-old (2.8\% of the population) [3]. 10 years from now those aged over 75 years will be 668,267 , of which 480,748 will be over 80 years (3.9\% of the population) [2]. In addition to the increased longevity, there are other factors that will be more widespread in the population and therefore in dental patients also such as obesity and drug abuse. The will also be an increase in patients who are medically compromised but whose condition is stable. In this case, the needs and expectations of patients will be greater and will, therefore, require greater diligence on the part of the dentist and healthcare providers. The approach should be a holistic one and not one with concentrates solely on the oral health status of the patient.

The increase in the number of dental patients with changing lifestyles and of morbidity [4], especially the older wing, impose a general medical supervision of the patient $[5,6]$. This is to calibrate dental treatment according to the principle of risks versus benefits, but also to achieve greater success of the therapies provided and reduce the consequences or risks for the patient.

The key to success in the management of patients at risk is the accurate evaluation of the possibility of effectively accomplishing the dental treatment planned [7]. The risk analysis should take into account at least four factors:

1. Nature, severity and stability of the overall medical condition of the patient

2. Functional capacity of the patient

3. Emotional state of the patient

4. Type and complexity of the dental treatment plan (invasive or non-invasive).

The main precautions to be applied in patients at risk include an extended medical and dental anamnesis, combined with the 
observation of the patient aimed at recognizing conditions that could put the patient at risk. Some patients may experience local and general signs that may lead the clinician to the need for further study of their health status $[7,8]$. The simple observation of the face, neck, ears, eyes, and nails can, in fact, provide useful insights for further anamnestic but also suggest instrumental investigation. The dentist may evaluate the possible prescription of specific laboratory tests or ask for consultations by those doctors (or hospitals) who prescribed the therapy to the patient. The consultation of colleagues in other area of medicine (cardiology, orthopedic, neurologist, geriatrician, oncologist, and dermatologist) should be evaluated for a broader assessment of the patient's health condition and his compatibility with the intended therapies and treatments. This assessment will still be discretionary and based on the type and degree of invasiveness of the planned treatments [6]. It should be noted that any intervention that will involve breach the muco-gingival barrier and the potential exposure of the alveolar bone shall be assumed as invasive [8,9]. In this definition falls also scaling and root-planning and subgingival curettage [9].

There is no universally applicable formula for the most appropriate management of patients at risk [7,8]. Each case requires a careful clinical assessment of the benefits of a particular treatment against the possible risks to the patient and the probable rate of success. For example, a cardiac patient has a condition of limited risk when performing non-invasive dental treatments, such as X-rays and periodontal probing, because the patient has no reason to be anxious. The same patient, however, may have a higher risk if the dentist has to do multiple teeth extractions, resulting in a possible increase of anxiety. As a consequence, the dentist will have to carefully weigh the state of the patient to the dental treatment to be carried out.

The intent of this review is to provide guidelines for dentists who work in private practice. The approach taken with "healthy" patients does not differ from that to be taken in so-called "patients at risk." It should be noted however that adherence to guidelines does not relieve us as dentists of our professional liability. Indeed, there may be occasion where not following the guidelines is indicated because of the particular aspects of that individual case [8-10]. The practitioner retains the option not to treat the patient in the private practice if it is believed that the clinical risk or a medical emergency arising during the treatment could not be properly managed, and the dental treatment itself requires a higher level of protection such as in the a hospital setting with the simultaneous presence of other specialists. Even the dental code of ethics of the FDI World Dental Federation expressly states that the dentist has the right to decline to treat a patient, except for the provision of emergency care, for humanitarian reasons, or where the laws of the country dictate otherwise, and should refer for advice and/or treatment any patient requiring a level of competence beyond that held. The needs of the patient are the overriding concern and the dentist should refer for advice or the treatment any patient requiring a level of dental competence greater than he/she possesses [11].

\section{PRECAUTIONS}

The patient who is to be subjected to an examination and dental treatment should first have a complete survey of their medical history. This procedure must be done in two ways: In writing (via a custom form from the dental office) and orally (through an interview dentist - patient). It should not be overlooked that the patient does not have an obligation to report any existing condition to medical staff though. Respect for privacy [12] may require a private discussion to get intimate data which can have correlations with the global health status, such as previous abortions, seropositivity for HIV, that otherwise might be omitted.

The medical questionnaire will put to the patient questions regarding the overall situation, hospitalizations, previous surgeries under general anesthesia, current therapies, allergies, lifestyle habits then move on to the patient's dental medical history. The module, customized by the dental practice manager or dentists, has the advantage of being signed by the patient so that he becomes responsible for what he has reported or omitted to report. However, depending on the answers given and also to verify the patient's understanding of the questions, the dentist cannot leave the medical history survey solely to the form but will have to continue with an oral interview. As for informed consent [13-15], it is necessary for the clinician to be certain that the patient has understood the questions asked, also taking into account their cultural and psychophysical condition. It is not a coincidence that the anamnesis, i.e., medical history survey is a medical procedure and cannot be delegated to dental hygienists or dental assistants. The doctor guides the conversation and interview in order not to leave any doubts about what the patient reported. An incomplete or incorrect anamnestic investigation may lead to negligent conduct which the dentist may be asked to explain in civil and/ or criminal proceedings.

On the web, there are several forms and templates for medical/ dental history which can be downloaded and customized. It is always wise to edit them to customize the questions based on the type of dental practice and type of patient.

After analyzing the risk and deciding to undertake dental treatments in the private dental practice [16], the dentist has to communicate those risks to the patient during the compilation and signing of the informed consent form. The treatment options should also be envisaged, clarifying reasons for preferring one over another. It is also appropriate to specify for each chosen treatment what are the predictable and/or exceptional risks (defined in probabilistic terms), the benefits and the possible side effects. Among the alternative therapies may also be appropriate to encompass the non-execution of the proposed treatment [8]. 
Particular emphasis must be given to the following aspects:

- Explain, in essential terms, what is the treatment

- Type of anesthesia which will be used and risks

- Technical difficulties

- Probability of success

- Results achievable (partial and final, if applicable)

- Advantages

- Consequences of temporary or definitive treatment

- Complications and side effects

- Medications or dietary precautions that the patient will have to follow

- The need for any special treatment or follow-up.

\section{RECOGNIZE THE PATIENT AT RISK}

The increase in life expectancy in both healthy and "at risk" patients, together with lifestyle changes, have led to the increase of conditions which can affect the health of the patient, interacting at various levels, with the opportunities and quality of dental treatments. The list of diseases that must be evaluated by the dentist during the medical history interview are already over thirty: Heart (infective endocarditis, hypertension, angina pectoris, previous infarction, arrhythmia), respiratory failure (chronic airway obstruction, asthma, sleep apnea), tuberculosis, liver disease (hepatitis B, C, D, E, cirrhosis), peptic ulcer disease, kidney disease, infectious diseases (gonorrhea, syphilis, HIV, human papillomavirus, AIDS), diabetes, leukemia, blood disorders (thrombocytopenia, hemophilia, coagulation disorders, edema angioneurotic edema), multiple myeloma, and neurological disorders $[7,17]$. Other conditions must be known to the dentist to tailor the treatment: Abuse of alcohol or tobacco; dialysis, transplants, hyperthyroidism, anemia, anorexia, anticoagulant therapy and bisphosphonates, pregnancy and lactation $[7,18]$. All these systemic diseases and conditions should be carefully explored by the dentist during the anamnestic investigation [16]. At the same time, a risk analysis in relation to the type/quality of dental treatments chosen and the potential to deal with emergencies occurring the dental practice. For this purpose, it is essential for oral health professionals to be adequately trained in the field of general health disorders, to become more aware of patient safety during dental treatment $[19,20]$.

The recognition of a patient at risk will continue with the overall assessment to check any general conditions reported voluntarily, or those present but unnoticed or have been underestimated by the patient himself. The observation of visible parts of the head, neck, ears, nails for any abnormalities that may be signs of systemic disease. A thickening of the mail could indicate, for example, a condition of cardiopulmonary insufficiency; or retraction of the eyelids may indicate a condition of hyperthyroidism; the observation of the ear could indicate signs of heart disease through the presence of a typical fold of the lobe; angioma in the typical "spider" pattern (spider angioma) is indicative of chronic liver disease [7].

Once the patient has been assessed, the dentist will check the suitability of performing the dental treatment within the private practice, considering the classification proposed by the American Society of Anesthesiology [21]. This assessment will depend on the knowledge, training and experience in the management of medical emergencies, including drugs and equipment for resuscitation. However, it is not the condition of "patient at risk" which leads to his referral to a hospital, but a more complex evaluation that involves the appraisal of the degree of urgency and invasiveness of dental care required. For this reason, it is useful to understand the reason for the dental visit - including dental history - and then to complete the assessment with the clinical examination of oral health for the purpose of diagnosing the dental treatments required for the best dental fitness, focusing on the masticatory function.

The dentist must also manage expectations of the patient taking their emotional state into account and evaluating them on the basis of the magnitude of dental procedures which need to be performed.

The dentist should not be embarrassed to explain the patient the opportunity of having health care assistance in a more complex facility because of the need of contextual assistance of specialists from other medical branches, pointing out that the general risks associated with any dental treatment that are not compatible with dental private practice [22].

\section{MEDICO-LEGAL CONSIDERATIONS}

There is no universally applicable formula for the most appropriate management of patients at risk. Each case requires a careful clinical assessment of the benefits of a specific treatment which considers the possible risks, the patients state of general health explored during the medical history interview and the clinical oral findings, together with a symmetrical consultation with other specialists who assist the same patient [7]. This is particularly indicated for those patients under cardiological, neurological, or orthopedic supervision $[23,24]$.

A risk analysis must to be performed to decide the most appropriate treatment. Framed the patient the necessary dental treatment can be decided on, the managing of any potential clinical risk or possible medical emergencies must also be considered [25]. The suitability of dental treatment in the private practice will only be decided on after the careful evaluation of numerous variables. The type and degree of invasiveness of dental care; length of time required to carry out the procedures and treatment options. training of oral health professionals in the field of medical emergencies; the availability of devices for monitoring vital functions and/or for rapid diagnosis (pressure, heart rate, oxygen saturation, blood glucose, pressure, clotting time); such as defibrillators' (oxygen, automated external defibrillator). If the dental practice is not equipped to treat patients at risk, it is preferable to refer him to a more complex health care facility or a public dental clinic.

It is appropriate, even on medico-legal grounds, to prove that a complete medical and dental history has been performed by means of a form signed by the patient [26]. It is also advisable 
to record the details of doctors consulted to discuss the general health status of the patient, with regard to systemic diseases referred by the patient. This is also mandatory if the need to modify or interrupt general therapies arises, such as in the case of anticoagulants and bisphosphonates [23,24].

When treating the patient at risk all metabolic values and vital signs should be previously monitored and measured to check the stability of systemic conditions and their suitability for treatment. In the market, there are numerous devices for real-time monitoring of vital signs (oxygen saturation, heart rate, blood pressure) and for the rapid diagnosis of metabolic values (clotting time, blood sugar). In addition, depending also on the local health legislation, the dentist could also equip the office with a semi-automatic defibrillator after having followed the appropriate course. These are choices that the dentist will evaluate based on the orientation and organization of his dental practice and its specializations.

The activity of the dentist, like any other doctor, aims at the protection of health and is carried out in relation to a patient who, especially if at risk, must be considered as vulnerable. In the treatment of patients at risk evidence of the diligence applied by the dentist will be essential for the defense any civil or penal litigation in the field of professional liability.

\section{CONCLUSIONS}

The main precaution when handling the medically compromised patient is a comprehensive medical approach and not based solely on the dental aspects, with the aim of a safe treatment and avoiding professional liability complaints. The starting point is the widest possible evaluation of the patient through an extended general medical and dental history. This approach will also raise the professional quality of service and prestige of the dental practice. The anamnestic investigation, conducted exclusively by dental practitioners, but shared with any other oral health-care professionals within the practice, plus any other additional investigations, such as consultation with other specialists, will help identify the risks and benefits of a specific treatment plan customizing it to the conditions and real needs of the patient. The patient must receive adequate information of the benefits of the proposed dental treatment plan highlighting any possible complications or risks and side effects of the treatments. Alternative therapeutic options, including the non-execution of any dental treatment should be considered including the need for another consultation with specialists in specific fields. This approach will not only assist in accomplishing the therapeutic doctor-patient alliance, but also the ethical and medico legal obligation coming from the informed consent.

\section{REFERENCES}

1. World Health Statistics. World Health Organization 2014. Risk Factors. 2014. p. 40-43, 116. Available from: http://apps.who.int/iris/ bitstream/10665/112738/1/9789240692671_eng.pdf. [Last accessed on 2015 May 01].

2. Istituto Nazionale di Statistica ISTAT, Health for All - Italia. 31 July, 2014. Available from: http://www.istat.it/it/archivio/14562. [Last accessed on 2015 Aug 01].

3. Istituto Nazionale di Statistica ISTAT. Available from: http://www. demo.istat.it. [Last accessed on 2015 May 01].

4. Math SS. Textbook of Preventive and Community Dentistry. New Delhi: Elsevier, India; 2011. p. 9-13.

5. Johnson NB, Hayes LD, Brown K, Hoo EC, Ethier KA. CDC National Health Report: Leading Causes of Morbidity and Mortality and Associated Behavioral Risk and Protective Factors - United States, 2005-2013. In: Morbidity and Mortality Weekly Report. Vol. 63. 2014. p. 3-27. Available from: http://www.cdc.gov/mmwr/preview/ mmwrhtml/su6304a2.htm. [Last accessed on 2015 Dec 01].

6. Al-Nawas B, Grötz KA. Medically compromised patients in the dental office: Demographics and progress in health care. Bundesgesundheitsblatt Gesundheitsforschung Gesundheitsschutz 2011;54:1066-72.

7. Littlle JW, Falace DA, Miller CS, Rhodus NL. Dental Management of the Medicallly Compromised Patient. St. Louis, MO: Elsevier, Mosby; 2012.

8. McCarthy FM. Recognition, assessment and safe management of the medically compromised patient in dentistry. Anesth Prog $1990 ; 37: 217-22$

9. Littlle JW, Falace DA, Miller CS, Rhodus NL. Dental Management of the Medically Compromised Patient. St. Louis, MO: Elsevier, Mosby; 2012.

10. Buccelli C, Graziano V, Lorenzo DP. Odontoiatria difensiva, defensive dentistry. In: Buccelli C, Michele DP, Laino A, editors. Orthodontics, Law and Forensic Medicine. Professional liability and pofessional connections in Orthodontics. Modena: Edizioni Martina; 2012. p. 326.

11. Williams JR. Dental Ethics Manual. FDI World Dental Federation; 2007 Available from: http://www.fdiworldental.org/media/70462 / 1-fdi dental_ethics_manual_1st_edition_2007.pdf. [Last accessed on 2015 Dec 01].

12. Spinas E, Ricci P, Nuzzolese E. Gestione e riservatezza dei dati personali del paziente nello studio professionale ortodontico, Management and privacy patient data in the orthodontic practice. In: Buccelli C, Di Michele P, Laino A, editors. Orthodontics, Law and Forensic Medicine. Professional liability and pofessional connections in Orthodontics.. Modena: Edizioni Martina; 2012. p. 192-3.

13. Rini MS. II consenso informato in odontoiatria: Problemi pratici e valenza legale ed assicurativa, Informed consent in dentistry: practical problems and legal and insurance sense, TAGETE 1-2007, Anno XIII.

14. Story RD. Medico-legal aspects of dental treatment of the ageing and aged patient. Aust Dent J 2015;60:64-70.

15. Woodman RC, Malz VL. Informed consent and the elderly dental patient. Spec Care Dentist 1994;14:65-7.

16. Silvestre-Rangil J, Silvestre FJ, Espín-Gálvez F. Hospital dental practice in special patients. Med Oral Patol Oral Cir Bucal 2014;19:163-9.

17. Gupta A, Epstein JB, Cabay RJ. Bleeding disorders of importance in dental care and related patient management. J Can Dent Assoc 2007;73:77-83. Available from: http://www.cda-adc.ca/jcda/vol-73/ issue-1 / 77.pdf. [Last accessed on 2015 Dec 01].

18. Pototski M, Amenábar JM. Dental management of patients receiving anticoagulation or antiplatelet treatment. J Oral Sci 2007;49:253-8.

19. Yamalik N, Perea Pérez B. Patient safety and dentistry: What do we need to know? Fundamentals of patient safety, the safety culture and implementation of patient safety measures in dental practice. Int Dent J 2012;62:189-96.

20. Dolan TA. Professional education to meet the oral health needs of older adults and persons with disabilities. Spec Care Dentist 2013:33:190-7.

21. Jackson DL, Johnson BS. Conscious sedation for dentistry: Risk management and patient selection. Dent Clin North Am 2002; 46:767-80

22. Renton T, Woolcombe S, Taylor T, Hill CM. Oral surgery: Part 1. Introduction and the management of the medically compromised patient. Br Dent J 2013;215:213-23.

23. Ministero del Lavoro, della Salute e delle Politiche Sociali, Dipartimento della qualità, Ufficio III, Raccomandazione per la prevenzione dell'osteonecrosi per la macella/mandibola da Bifosfonati; 2009. Available from: http://www.salute.gov.it/ imgs/C 17_pubblicazioni_1077_allegato.pdf. [Last accessed on 2015 Dec 01].

24. Fedele S, Kumar N, Davies R, Fiske J, Greening S, Porter S. Dental management of patients at risk of osteochemonecrosis of the jaws: 
A critical review. Oral Dis 2009; 15:527-37.

25. Ministero del Lavoro, della Salute e delle Politiche Sociali, Dipartimento Della Qualità, Ufficio III, Sicurezza Dei Pazienti e Gestione Del Rischio Clinico: Manuale Per la Formazione Degli Operatori Sanitari. Available from: http://www.salute.gov.it/imgs/C_17_pubblicazioni_640_ allegato.pdf. [Last accessed on 2015 Dec 01].
26. Kosyfaki P, Att W, Strub JR. The dental patient on oral anticoagulant medication: A literature review. J Oral Rehabil 2011;38:615-33.

Source of Support: Nil, Conflict of Interest: None declared. 